\title{
Trends in descriptions of palliative care in the cancer clinical practice guidelines before and after enactment of the Cancer Control Act (2007): content analysis
}

Miwa Hinata ${ }^{1,2},{\text { Kikuko Miyazaki }{ }^{2} \text {, Natsuko Kanazawa }}^{2,3}$, Kumiko Kito $^{2,4}$, Sachiko Kiyoto ${ }^{5}$, Manako Konda ${ }^{2,6}$, Akira Kuriyama ${ }^{2}$, Hiroko Mori ${ }^{2,7}$, Sachiko Nakaoka ${ }^{2}$, Akiko Okumura ${ }^{2,8}$, Hironobu Tokumasu ${ }^{9}$ and Takeo Nakayama ${ }^{2}$

\begin{abstract}
Background: Palliative care was a priority issue in the Cancer Control Act enacted in 2007 in Japan, and this has resulted in efforts being made toward educational goals in clinical settings. An investigation of how descriptions of palliative care for the treatment of cancer have changed in clinical practice guidelines (CPGs) could be expected to provide a better understanding of palliative care-related decision-making. This study aimed to identify trends in descriptions of palliative care in cancer CPGs in Japan before and after enactment of the Cancer Control Act.

Methods: Content analysis was used to count the lines in all relevant CPGs. We then compared the number of lines and the proportion of descriptions mentioning palliative care at two time points: the first survey (selection period: February to June 2007) and the second survey (selection period: February to December 2015). Descriptions from the CPGs were independently selected from the Toho University Medical Media Center and Medical Information Network Distribution Service databases, and subsequently reviewed, by two investigators.

Results: Descriptions were analyzed for 10 types of cancer. The proportion of descriptions in the first survey (4.4\%; 933/21,344 lines) was similar to that in the second survey (4.5\%; 1325/29,269 lines).

Conclusions: After the enactment of the Cancer Control Act, an increase was observed in the number, but not in the proportion, of palliative care descriptions in Japanese cancer CPGs. In the future, CPGs can be expected to play a major role in helping cancer patients to incorporate palliative care more smoothly.
\end{abstract}

Keywords: Palliative care, Cancer clinical practice guideline, Cancer control act [2007], Content analysis, Qualitative research

\section{Background}

According to the Institute of Medicine in the United States, clinical practice guidelines (CPGs) are statements that include recommendations intended to optimize patient care [1]. They are informed by a systematic review of evidence and an assessment of the benefits and harms of alternative care options. CPGs generally cover $60-95 \%$ of clinical conditions [2]. After a 1997 report on the assessment of health technology by a working group of the

\footnotetext{
*Correspondence: miy@plum.ocn.ne.jp

${ }^{2}$ Department of Health Informatics, Kyoto University School of Public Health,

Yoshida honcho sakyo-ku, Kyoto, Japan

Full list of author information is available at the end of the article
}

Ministry of Health, Labour and Welfare in Japan, [3] the development of CPGs began to increase in 1999 [4]. CPGs in many medical disciplines, including cancer, have now been developed, mainly by academic and professional associations, using evidence-based approaches $[5,6]$. CPGs are periodically revised to include the most up-to-date information [7]. These CPGs help support clinical decision-making and advocate the role of continuing education for healthcare providers [8].

In 1981, cancer surpassed stroke as the leading cause of death in Japan [9]. Cancer is a major health concern among people in Japan. For healthcare systems, a quantitative infrastructure (e.g., cancer screening) has been under

(c) The Author(s). 2019 Open Access This article is distributed under the terms of the Creative Commons Attribution 4.0 International License (http://creativecommons.org/licenses/by/4.0/), which permits unrestricted use, distribution, and 
constant development since 1984; however, the qualitative infrastructure (e.g., patients and support from their families) remains insufficient [10]. Enacted in 2007, the Cancer Control Act [11] aims to promote comprehensive planning for cancer management based on cancer prevention, early cancer detection, furthering cancer research, and eliminating disparities in cancer treatment [11]. Cancer control programs emphasize palliative care as a priority issue and aim at "promoting palliative care from the time when cancer is diagnosed" [11, 12]. An investigation of how descriptions of palliative care have changed in cancer CPGs in Japan could provide a better understanding of palliative care-related decision-making in clinical practice $[1,13,14]$.

A study reviewing 91 CPGs for nine life-threatening diseases (including breast, colorectal, prostate, and lung cancers) published between 1987 and 2002 in the United States reported that palliative and end-of-life care were seldom mentioned [15]. However, no similar studies have previously been reported in Japan. Therefore, the aim of the present study was to identify trends in descriptions about palliative care in Japanese cancer CPGs before and after enactment of the Cancer Control Act in 2007.

\section{Methods}

\section{Design}

In the present study, we used content analysis of existing literature $[16,17]$ to compare the number of lines and proportion of descriptions mentioning palliative CPGs before and after enactment of the Cancer Control Act in 2007.

The first survey (selection period: February to June 2007) Cancer CPGs published between January 2002 and December 2006 were analyzed. Databases from the Toho University Medical Media Center [18] (search date: January 18, 2007) and the Medical Information Network Distribution Service (MINDS) [19, 20] were reviewed. Assuming that the cancer CPGs were tools to provide information sharing for decision-making by healthcare providers, patients, and their families, cancer CPGs that were available not only to healthcare providers, but also to the general public, were selected. The following cancer CPGs were excluded from analysis: 1) those from foreign countries that were translated into Japanese, 2) those developed for the purpose of using specific cancer treatment regimens, for example, "for optimal use of a specific anticancer drug" or "for appropriate use of thalidomide in multiple myeloma", 3) those not readily available to the general public, for example, "Cancer CPGs published in academic or professional journals", and 4) guideline manuals. Palliative care was defined based on previous reports, [13] namely, as "care given to a patient when there is no response to curative treatment and life-expectancy is less than one year." We defined 17 criteria for selecting palliative care descriptions from cancer CPGs (Table 1).
Table 1 Domains of palliative care

\begin{tabular}{|c|c|}
\hline 1. & $\begin{array}{l}\text { Non-pain symptom assessment and management } \\
\text { (dyspnea, nausea and vomiting, delirium, fatigue, etc.) }\end{array}$ \\
\hline 2. & Pain assessment and management \\
\hline 3. & $\begin{array}{l}\text { Natural history (prognosis, time course, mode of death, } \\
\text { and symptoms) }\end{array}$ \\
\hline $4 .^{a}$ & Palliative care \\
\hline 5. ${ }^{a}$ & Palliative operation/symptomatic treatment \\
\hline 6. & $\begin{array}{l}\text { Necrology (death statistics, including gender, age } \\
\text { at death, any racial disparities) }\end{array}$ \\
\hline 7. & $\begin{array}{l}\text { Social issues (interpersonal relationships with spouses or } \\
\text { partners, family, and friends supporting these relationships) }\end{array}$ \\
\hline 8. & $\begin{array}{l}\text { Care setting (option for location of end-of-life care, referral } \\
\text { to hospice, funeral arrangements) }\end{array}$ \\
\hline 9. & $\begin{array}{l}\text { Psychological issues (depression, anxiety, fear, loneliness, } \\
\text { emotional awareness) }\end{array}$ \\
\hline 10. & $\begin{array}{l}\text { Financial issues (cost to patient and family, not insurer } \\
\text { or societal cost) }\end{array}$ \\
\hline 11. & $\begin{array}{l}\text { Patient or family values (any discussion regarding patient } \\
\text { and/or family goals and values, including advanced } \\
\text { directives and "do not resuscitate" orders) }\end{array}$ \\
\hline 12. & $\begin{array}{l}\text { Goal of care (goals of care related to quality of life and } \\
\text { end-of-life care) }\end{array}$ \\
\hline 13. & $\begin{array}{l}\text { Physician communication with patient/family (including } \\
\text { communication with patient and family about personal } \\
\text { grief and bereavement) }\end{array}$ \\
\hline 14. & $\begin{array}{l}\text { Ethics, laws, and policies (individual vs. organization } \\
\text { ethics, patients' self-determination, double effect, legal } \\
\text { aspects of withdrawal, and withholding of life support) }\end{array}$ \\
\hline 15. & $\begin{array}{l}\text { Physician roles in advocacy and policy (including } \\
\text { pronouncement, autopsy, organ donation, advocacy, } \\
\text { and changing institutional policy) }\end{array}$ \\
\hline 16. & $\begin{array}{l}\text { Spiritual issue (abandonment, completion of tasks, } \\
\text { acceptance, religious tasks, and choices) }\end{array}$ \\
\hline 17. & $\begin{array}{l}\text { Family roles and responsibilities (communication of } \\
\text { patient and family member roles during the process, } \\
\text { grief and bereavement, caregiver roles and support) }\end{array}$ \\
\hline
\end{tabular}

a' included the following two criteria: "Palliative care" and "Palliative operation/symptomatic treatment", which could not be classified by the 15 criteria; problems related to the boundary area are also included

Fifteen criteria were used based on those reported by Mast et al [13]. In addition, we included the following two criteria: "Palliative care" and "Palliative operation/ symptomatic treatment", which could not be classified by the 15 criteria; we also included problems related to the boundary area. Selection was based on whether the descriptive content met the definitions and selection criteria. Even if "palliative care" was not directly mentioned, if the description corresponded to the selection criteria, it was selected for analysis. The amount of text was quantified as follows: 1) a single word matching one of 17 criteria was counted as one; 2) the total number of lines of relevant descriptions describing one of the 17 criteria was counted; and 3) the context of references to the cancer pain guidelines by the Japanese Society for 
Palliative Medicine, $[21,22]$ as well as a description of participation of the society on "guideline executive committee" and "external review committee" and "guideline development committee"; 4) descriptions of "palliative care from the time when cancer is diagnosed" after enforcement of the Cancer Control Act; and 5) presence of the following four terms: palliative care, best supportive care (BSC), palliative therapy, and symptomatic treatment.

The proportion of descriptions was calculated by dividing by the total number of lines for each criterion. Since Japanese cancer CPGs are in the same form, we adopted this method to compare quantitatively the number of descriptions of palliative care. We defined two classifications: "minimal content", which referred to words that did not include any specific information regarding the 17 criteria, and "helpful content", which referred to a description that included specific and useful information about the 17 criteria. If classification between "minimal content" and "helpful content" was difficult, we classified the description as "helpful content". Descriptions were independently selected from each CPG by two investigators.

These data were then compared by the two investigators, and any disagreement was resolved through discussion before the data analysis. If any discrepancies between the two investigators remained, a consensus was reached through deliberation with all study members.

\section{The second survey (selection period: February to} December 2015)

We evaluated the most current versions of the CPGs at the time of review in 2015 (search date: March 4, 2015). The data were analyzed in the same manner as that in the first survey.

\section{Results}

\section{Selected clinical practice guidelines (CPGs)}

Among 47 cancer CPGs in the first survey, 35 were excluded based on the exclusion criteria; therefore, we finally analyzed 12 CPGs for the following 10 types of cancer: esophageal, gastric, breast (chemotherapy, surgery, and radiation therapy), colorectal, lung, liver, prostate, pancreatic, uterine, and ovarian (Fig. 1). In the second survey, CPGs for the same types of cancer included in the first survey were examined (Table 2). However, the editing formats for the breast cancer CPGs differed between the first and second surveys. Among all five separate volumes of breast cancer CPGs (chemotherapy, radiation therapy, surgery, epidemiology/diagnosis, and prevention) in the first survey, we analyzed three volumes (chemotherapy, radiation therapy, and surgery). For the second survey, we analyzed the treatment volume among two volumes (the other was for diagnosis). All CPGs were developed by relevant clinical societies.

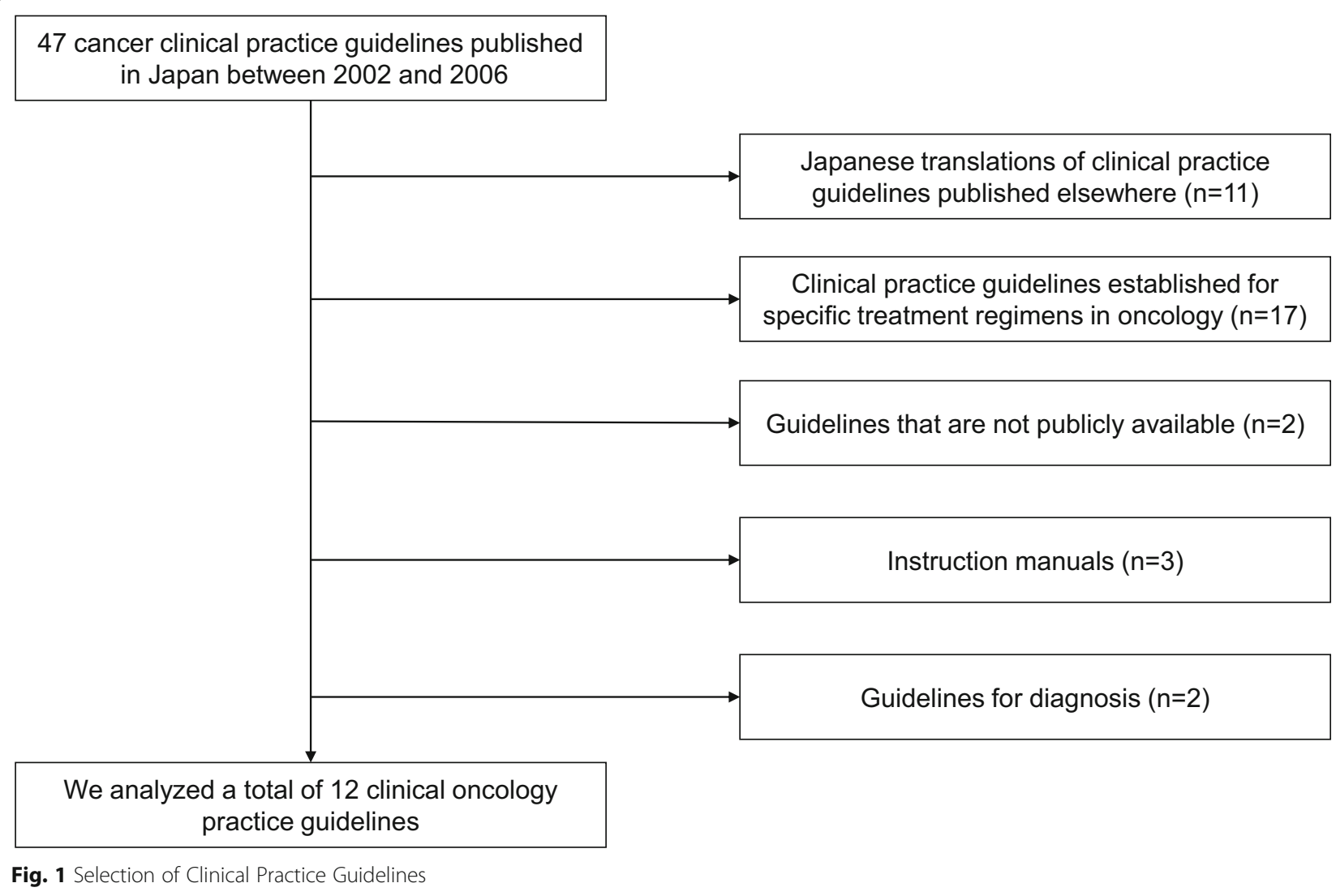


Table 2 Editor and publication year of the clinical practice guidelines (CPGs) (Japanese)

\begin{tabular}{|c|c|c|c|}
\hline Guideline & 2007 survey (Edition) & 2015 survey (Edition) & Editor \\
\hline $\begin{array}{l}\text { Guidelines for Diagnosis and Treatment of } \\
\text { Carcinoma of the Esophagus }\end{array}$ & 2002 (1st) & $2012(3 r d)$ & The Japan Esophageal Society \\
\hline Gastric Cancer treatment guidelines & 2004 (2nd) & 2014 (4th) & Japanese Gastric Cancer Association \\
\hline Guideline for Ovarian Cancer Treatment & 2004 (1st) & $2010(3 r d)$ & The Japan Society of Gynecologic Oncology \\
\hline \multirow[t]{3}{*}{$\begin{array}{l}\text { The Japanese Breast Cancer Society Clinical } \\
\text { Practice Guideline }{ }^{a}\end{array}$} & $\begin{array}{l}\text { Chemo } \\
2004 \text { (1st) }\end{array}$ & \multirow{3}{*}{$\begin{array}{l}2013 \\
\text { (Chemo 4th) } \\
\text { (Radiation 3rd) } \\
\text { (Surgery 3rd) }\end{array}$} & \multirow[t]{3}{*}{ The Japanese Breast Cancer Society } \\
\hline & $\begin{array}{l}\text { Radiation } \\
2005 \text { (1st) }\end{array}$ & & \\
\hline & $\begin{array}{l}\text { Surgery } \\
2005 \text { (1st) }\end{array}$ & & \\
\hline $\begin{array}{l}\text { JSCCR Guidelines for the Treatment of } \\
\text { Colorectal Cancer }\end{array}$ & 2005 (1st) & 2014 (3rd) & $\begin{array}{l}\text { The Japanese Society for Cancer of the } \\
\text { Colon and Rectum }\end{array}$ \\
\hline $\begin{array}{l}\text { Guideline for Diagnosis and Treatment of } \\
\text { Lung Cancer }\end{array}$ & 2005 (2nd) & 2014 (3rd) & The Japan Lung Cancer Society \\
\hline $\begin{array}{l}\text { Clinical Practice Guidelines for Hepatocellular } \\
\text { Carcinoma }\end{array}$ & 2005 (1st) & 2013 (3rd) & The Japan Society of Hepatology \\
\hline $\begin{array}{l}\text { Evidence-based Clinical Practice Guidelines for } \\
\text { Prostate Cancer }\end{array}$ & 2006 (1st) & 2012 (2nd) & The Japanese Urological Association \\
\hline EBM-based Clinical Guidelines for Pancreatic Cancer & 2006 (1st) & $2013(3 r d)$ & Japan Pancreas Society \\
\hline $\begin{array}{l}\text { Evidence-based Guidelines for Treatment of } \\
\text { Uterine Body Neoplasm }\end{array}$ & 2006 (1st) & $2013(3 r d)$ & The Japan Society of Gynecologic Oncology \\
\hline
\end{tabular}

${ }^{a}$ Among all five breast cancer CPGs (chemotherapy, radiation therapy, surgery, epidemiology/diagnosis, and prevention), we analyzed three volumes (chemotherapy, radiation therapy, and surgery). The treatment sections from two CPGs (treatment, diagnosis) included similar content between the first and second surveys

\section{Proportion of palliative care descriptions}

We found 21,344 lines and 29,269 lines from all examined CPGs for first and second surveys, respectively. The total number of lines about palliative care in all guidelines increased from 933 in the first survey to 1325 in the second. However, the proportion of descriptions in the first survey $(4.4 \%)$ was very similar to that in the second $(4.5 \%)$ (Table 3). The number of "minimal content" descriptions increased 1.85-fold (from 75 to 139 lines) and the proportion of descriptions increased 1.34-fold (from 0.35 to $0.47 \%$ ). The number of "helpful content" descriptions increased 1.38 -fold (from 858 to 1186 lines) and the proportion of descriptions increased 1.01-fold (from 4.01 to $4.05 \%$ ).

\section{Comparison of selected clinical practice guidelines (CPGs)}

Table 3 shows the number and proportion of descriptions by CPGs. Regarding the proportion of descriptions, that for ovarian cancer increased from 2.1\% (17/806 lines) to $5.1 \%$ (107/2113 lines), and that for prostate cancer from $6.5 \%$ (277/4272 lines) to 9.0\% (327/3646 lines). Conversely, that for pancreatic cancer decreased from $15.0 \%$ (152/1010 lines) to $9.1 \%$ (231/2552 lines), and that for gastric cancer from $14.3 \%$ (66/461 lines) to $5.6 \%$ (50/ 892 lines) (Table 3). Among all 12 CPGs in the first survey, the cancer pain guidelines from the Japanese Society for Palliative Medicine [21, 22] were only referred to in the prostate cancer CPG. However, in the second survey, this was referred to in five of the 10 CPGs (the prostate cancer, pancreatic cancer, colorectal cancer, gastric cancer, and esophageal cancer CPGs). In addition, the description of "palliative care from the time when cancer is diagnosed" stated in the Cancer Control Act was stipulated only in the colon CPG before implementation, compared with the esophageal cancer, stomach cancer, pancreatic cancer, and colon cancer CPGs after implementation. Furthermore, in the second survey, the number of guidelines describing the terms "palliative care", "best supportive care (BSC)", and "symptomatic treatment" had increased (Table 4).

We confirmed the CPGs for the two sessions in 2007 and 2015 that were covered for the three points of the society (guideline executive committee, external review committee, and guideline development committee) regarding the relationship with the Palliative Medical Society. As a result, we confirmed that there was no mention of these items in CPGs at either time point. In addition, there was no description as to whether the guideline creator was a member of the Japanese Society for Palliative Medicine.

\section{Examination of descriptions}

The most commonly mentioned items were "pain" and "non-pain symptoms", whereas four of the 17 items-"spiritual issues", "family roles and responsibilities", "ethics, laws, and policies", and "physician roles in advocacy and policy"-were never mentioned (Fig. 2). "Helpful content" about "palliative care", which provided information about best supportive care, controlled studies, and palliative 
Table 3 Comparison of the descriptions of palliative care in the clinical practice guidelines of 2007 and 2015

\begin{tabular}{|c|c|c|c|c|c|}
\hline Clinical practice guideline & Survey year & $\begin{array}{l}\text { Minimal content } \\
\text { (lines) }\end{array}$ & $\begin{array}{l}\text { Helpful content } \\
\text { (lines) }\end{array}$ & $\begin{array}{l}\text { Total volume of } \\
\text { guideline (lines) }\end{array}$ & $\begin{array}{l}\text { Palliative care } \\
\text { description }^{a}(\%)\end{array}$ \\
\hline \multirow[t]{2}{*}{ Prostate cancer } & 2007 & 24 & 253 & 4272 & 6.5 \\
\hline & 2015 & 15 & 312 & 3646 & 9.0 \\
\hline \multirow[t]{2}{*}{ Lung cancer } & 2007 & 15 & 128 & 3866 & 3.7 \\
\hline & 2015 & 9 & 98 & 3101 & 3.5 \\
\hline \multirow[t]{2}{*}{ Pancreatic cancer } & 2007 & 4 & 148 & 1010 & 15.0 \\
\hline & 2015 & 9 & 222 & 2552 & 9.1 \\
\hline \multirow[t]{2}{*}{ Gastric cancer } & 2007 & 2 & 64 & 461 & 14.3 \\
\hline & 2015 & 4 & 46 & 892 & 5.6 \\
\hline \multirow[t]{2}{*}{ Colorectal cancer } & 2007 & 15 & 70 & 758 & 11.2 \\
\hline & 2015 & 20 & 126 & 1551 & 9.4 \\
\hline \multirow[t]{2}{*}{ Uterine neoplasms } & 2007 & 2 & 35 & 1521 & 2.4 \\
\hline & 2015 & 15 & 26 & 2749 & 1.5 \\
\hline \multirow[t]{2}{*}{ Breast cancer } & 2007 & 8 & 91 & 3191 & 3.1 \\
\hline & 2015 & 21 & 110 & 7648 & 1.7 \\
\hline \multirow[t]{2}{*}{ Esophageal cancer } & 2007 & 0 & 56 & 599 & 9.3 \\
\hline & 2015 & 30 & 138 & 1802 & 9.3 \\
\hline \multirow[t]{2}{*}{ Ovarian cancer } & 2007 & 4 & 13 & 806 & 2.1 \\
\hline & 2015 & 8 & 99 & 2113 & 5.1 \\
\hline \multirow[t]{2}{*}{ Hepatocellular carcinoma } & 2007 & 1 & 0 & 4860 & 0.0 \\
\hline & 2015 & 8 & 9 & 3215 & 0.5 \\
\hline \multirow[t]{2}{*}{ Total } & 2007 & 75 & 858 & 21,344 & 4.4 \\
\hline & 2015 & 139 & 1186 & 29,269 & 4.5 \\
\hline
\end{tabular}

${ }^{a}$ we calculated palliative care descriptions (\%) by adding minimal content lines and helpful content lines divided by the total volume of lines

chemotherapy, was mentioned much more frequently in the second than in the first survey.

\section{Discussion}

Based on a comparison of cancer CPGs during two periods between 2007 and 2015, the number of palliative care descriptions increased as follows: 1.85-fold (from 75 to 139 lines) for "minimal content" and 1.38-fold (from 858 to 1186 lines) for "helpful content". In addition, since the implementation of the Cancer Control Act in 2007, the number of CPGs describing "palliative care from the time when cancer is diagnosed" had increased; thus, recognition of the concept has come a long way.

Table 4 Comparison of terms related to palliative care in the clinical practice guidelines

\begin{tabular}{lll}
\hline & $\begin{array}{l}2007 \text { survey } \\
\text { (guidelines) }\end{array}$ & $\begin{array}{l}2015 \text { survey } \\
\text { (guidelines) }\end{array}$ \\
\hline Palliative care & 8 & 9 \\
Best supportive care (BSC) & 3 & 7 \\
Palliative therapy & 8 & 7 \\
Symptomatic treatment & 4 & 5 \\
\hline
\end{tabular}

This development was probably influenced by the significant changes in healthcare policies regarding palliative care over the last 10 years in Japan. One of these changes was the Cancer Control Act, [11] which was enacted in 2007 to improve cancer management and eliminate disparities in cancer treatment. With the enactment of the Cancer Control Act, palliative care teams were established at cancer hospitals in each region as part of a system to provide more appropriate palliative care. In addition, to enable all physicians who care for cancer patients to learn the basic principles of palliative care, palliative care workshops as part of the "Palliative care Emphasis program on symptom management and Assessment for Continuous medical Education (PEACE) project" have been conducted throughout Japan [23]. Moreover, a website has been developed, primarily by the cancer information center at the National Cancer Center, to provide information to patients [24]. These changes in social attitudes were seen after the promulgation of the Cancer Control Act, and these changes could be one of the factors that promoted improvement in palliative care.

However, the proportion of palliative care descriptions remained almost the same (4.4 and $4.5 \%)$. The reasons 


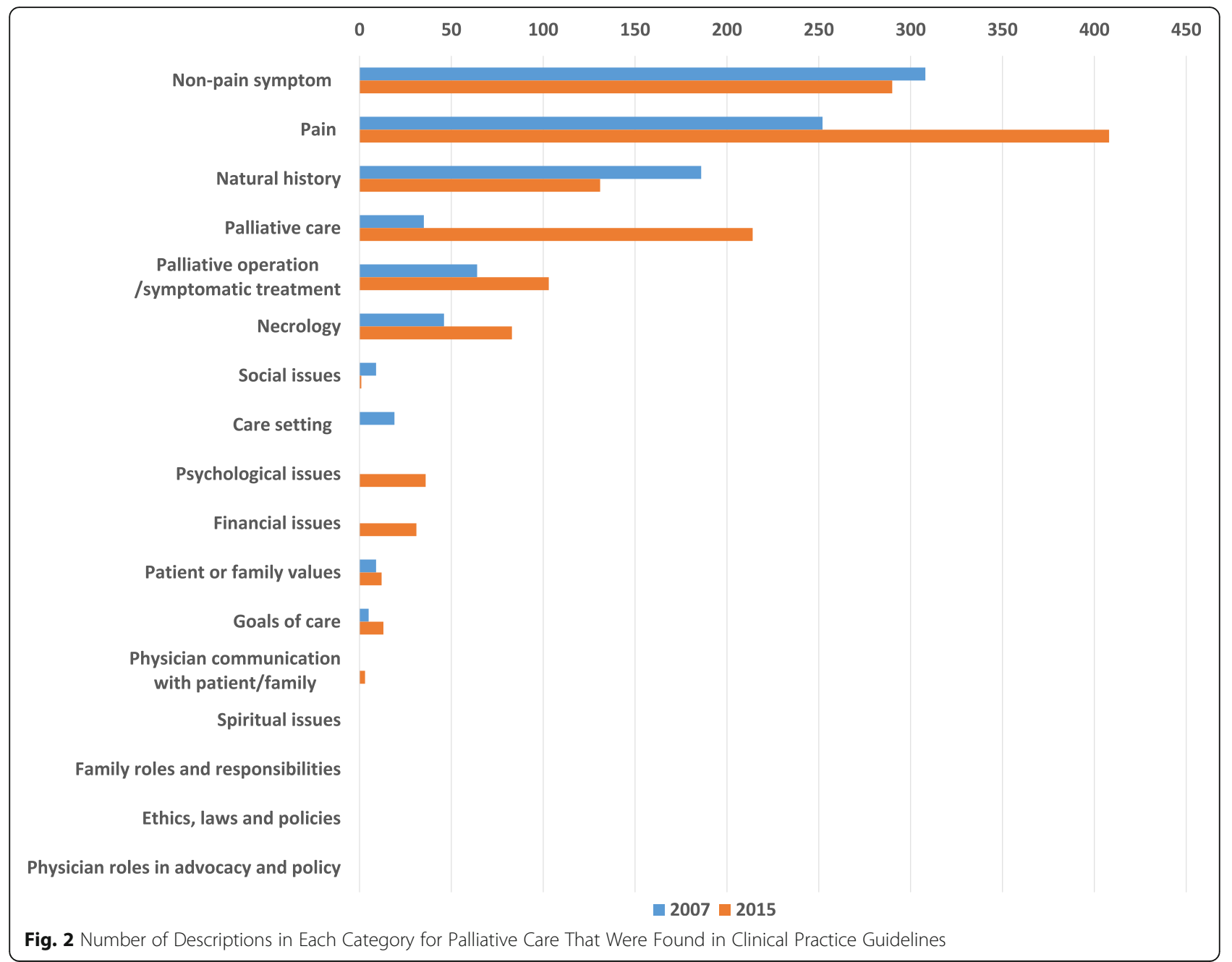

for this lack of substantial change in the proportion of descriptions are thought to be as follows: 1) there was a substantial increase in the total number of lines in CPGs, and 2) several CPGs encouraged reference to cancer pain guidelines (e.g., prostate cancer, pancreatic cancer, gastric cancer) [22]. In 2007, palliative care guidelines only described cancer pain treatment [21] in a single book. However, as of 2015, the following five CPGs were being widely used: drug therapy for cancer pain, [22] palliative sedation therapy, [25] gastrointestinal symptoms, [26] respiratory symptoms, [27] and infusion therapy [28].

From these circumstances, palliative care appears to be gaining more widespread attention. However, CPGs for palliative care are still developed independent of other cancer CPGs; no CPGs have been created by any cancer clinical society in collaboration with the Japanese Society for Palliative Medicine.

\section{Differences in cancer types}

The number and proportion of palliative care descriptions varied widely among the CPGs depending on the type of cancer (Table 3). For example, from 2007, the CPGs for prostate cancer, the progression of which is usually slow, continuously had the highest number of palliative care descriptions among the 10 types of cancer [24, 29]. Moreover, many of the descriptions in the prostate cancer CPGs have focused on "non-pain symptoms." As symptoms in prostate cancer progress, sexual function and urination are affected, bone metastases can occur, and quality of life (QOL) diminishes. Therefore, much has been written about palliative care to alleviate these symptoms.

On the other hand, the CPGs for hepatocellular carcinoma (HCC) had the fewest number of descriptions regarding palliative care. About $70-80 \%$ of HCC cases are associated with chronic hepatitis $\mathrm{B}$ or $\mathrm{C}$ infection, and there is often a long asymptomatic period [24]. Therefore, the HCC CPGs, rather than having descriptions about palliative care, had more descriptions about aggressive treatment such as hepatic resection and liver transplantation. 


\section{Specific descriptions}

In both the 2007 and 2015 surveys, the highest number of descriptions contained "helpful content", specifically in regard to "pain" (Fig. 2). The descriptions about "pain" included substantial information about specific treatments such as nerve blocks and radiation therapy for bone metastases. In addition, references were made to specific cancer pain guidelines [22] in terms of treating "pain." In a previous study, more than half of the CPGs discussed "natural history" and "non-pain symptoms" [13]. Our study investigated only cancer CPGs. Moderate to severe pain in cancer is common and affects $70-80 \%$ of patients with advanced disease, [30] so much has been written about "pain." However, in this study, hardly any descriptions were found regarding psychological, social, or spiritual distress. The reason for this is probably because there are very few randomized trials or high quality observational studies that assess whether palliative care contributes to improved QOL in cancer patients [31, 32]. Descriptions of the above issues can be expected to increase as more high-quality evidence is acquired.

\section{CPGs in shared decision-making}

Since the Cancer Control Act was enacted in 2007, CPGs describing terms related to palliative care have increased, and interest in palliative care appears to be increasing.

In palliative care, communication between the patient and the physician is important to understand patients' intentions about where and how they wish to approach the end of life and whether these wishes can be carried out [33]. In helping patients and their families prepare for the end of life, CPGs, as decision-making support tools, must serve as a basis for shared decision-making among patients, their families, and healthcare providers. Cancer CPGs need be developed as support tools for palliative care communication between patients and physicians.

\section{Study limitations}

This study was conducted using content analysis, with "line" used as a concrete index for the number of descriptions of "palliative care". Although a consensus of definitions was reached among the co-investigators, there may have been some variation in the classifications. For example, for cancers with relatively gradual progression such as prostate cancer, there was often a direct mention of the "mortality rate." Conversely, for cancers with rapid progression, such as pancreatic cancer, the use of the word "prognosis" to convey remaining time was noted. This may have resulted from different framing by investigators regarding the characteristics of cancer progression. In these instances, although mortality rate in "necrology" and prognosis in "natural history" may have similar meanings, they were counted as separate items. Thus, when a similar circumstance was expressed in two different ways, selected items may have been divided. Therefore, these variations were taken into consideration, and the results were carefully interpreted in relation to differences in the proportion of descriptions. In addition, if classification of "minimal content" and "helpful content" was difficult, it was regarded as "helpful content" This may account for the increased amount of "helpful content". However, even when the above considerations were taken into account, a comparison between the two survey periods showed an increasing trend in the number of palliative care descriptions in the CPGs.

As a method of analysis, we used "content analysis," which is an established qualitative analysis method. Therefore, our analysis is based on only the information included in CPGs. In AGREE II, which is a popular method for evaluating CPGs, only the content of description in CPGs is checked. Therefore, there is no target of analysis other than the information described above.

We considered palliative care as "care given to a patient when there is no response to curative treatment and life expectancy is less than one year" based on the content of cancer control programs, the situation in Japan in 2007, and descriptions in a previous study [13]. Although this definition does not correspond with the description "palliative care from the time when cancer is diagnosed" used in cancer control programs, we believe that indications in cancer diagnoses regarding how the perception of palliative care changed before and after the Cancer control Act have been enforced.

\section{Conclusions}

After enactment of the Cancer Control Act, an increase was observed in the number but not in the proportion of palliative care descriptions in Japanese cancer CPGs. In the future, CPGs can be expected to play a role in helping cancer patients to incorporate palliative care smoothly by collaborating with individual clinical societies for various types of cancer and the Japanese Society for Palliative Medicine, which provides common ground.

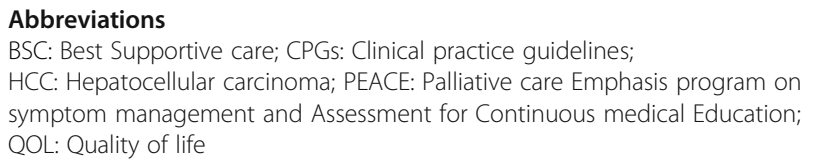

Funding

This work was supported by JSPS KAKENHI Grant Number 24390128 and JSPS KAKENHI Grant Number 18H03023.

Availability of data and materials

All data analyzed during this study are included in published clinical practice guidelines in Japan. 


\section{Authors' contributions}

$\mathrm{KM}$ and TN conceived the study design. MH, KM, NK, KK, SK, MK, AK, HM, SN, $\mathrm{AO}$, and $\mathrm{HT}$ participated in data acquisition. $\mathrm{MH}$ and $\mathrm{KM}$ analyzed and interpreted the data. $\mathrm{MH}, \mathrm{KM}$, and TN wrote the first draft. All authors participated in critical revisions of the manuscript and approved the submission of the current manuscript.

\section{Ethics approval and consent to participate}

Not applicable.

\section{Consent for publication}

Not applicable.

\section{Competing interests}

The authors declare that they have no competing interests with respect to the research, authorship, and publication of this article.

\section{Publisher's Note}

Springer Nature remains neutral with regard to jurisdictional claims in published maps and institutional affiliations.

\begin{abstract}
Author details
'Department of Hospital Pharmaceutics, Showa University, Tokyo, Japan. ${ }^{2}$ Department of Health Informatics, Kyoto University School of Public Health, Yoshida honcho sakyo-ku, Kyoto, Japan. ${ }^{3}$ Clinical Research Center, National Hospital Organization, Tokyo, Japan. ${ }^{4}$ Department of Food and Life science, Azabu University, Kanagawa, Japan. ${ }^{5}$ Department of Breast Oncology, National Hospital Organization Shikoku Cancer Center, Ehime, Japan. ${ }^{6}$ Department of Preventive Services, Kyoto University School of Public Health, Kyoto, Japan. ${ }^{7}$ Tokyo Metropolitan Institute of Gerontology Human care research Team, Tokyo, Japan. ${ }^{8}$ Department of EBM and Guidelines, Japan Council for Quality Health Care, Tokyo, Japan. ${ }^{9}$ Department of Consultation, Kurashiki Clinical Research Institute, Okayama, Japan.
\end{abstract}

Received: 13 August 2018 Accepted: 7 January 2019

Published online: 12 January 2019

\section{References}

1. Institute of Medicine. Clinical Practice Guidelines We Can Trust. 2011. Retrieved from http://iom.nationalacademies.org/Reports/2011/ClinicalPractice-Guidelines-We-Can-Trust . Accessed 11 June 2019.

2. Eddy DM. Clinical decision making: from theory to practice. Designing a practice policy. Standards, guidelines, and options. JAMA. 1990;263(22) 3077, 3081, 3084.

3. Ministry of Health, Labour and Welfare. Report about Needs and Future Direction of Health Technology Assessment, Committee for Examination of Health Technology Assessment, 23 Mar 1999 (in Japanese). Retrieved from https://www.mhlw.go.jp/www1/houdou/1103/h0323-1_10.html . Accessed 11 June 2019.

4. Kojimahara N, Okumura A, Takahashi N, et al. Current situation of evidencebased clinical practice guidelines in Japan. Gen Med. 2012;35:195-203.

5. Nakayama T, Budgell B, Tsutani K. Confusion about the clinical practice guidelines in Japan: on the way to a social consensus. Int J Qual Health Care. 2003;15:359-60.

6. Nomura $\mathrm{H}$, Nakayama $\mathrm{T}$. The Japanese healthcare system: the issue is to solve the "tragedy of the commons" without making another [editorial]. BMJ. 2005;331:648-9.

7. Minds Guideline Center, Japan Council for Quality Health Care. Minds Handbook for Clinical Practice Guideline Development. Retrieved from http://minds4.jcqhc.or.jp/minds/guideline/pdf/MindsHB2014.pdf . Accessed 11 June 2019

8. National Institute for Health and Care Excellence. The guidelines manual, November 2012. Retrieved from https://www.nice.org.uk/process/pmg6/ chapter/introduction. Accessed 11 June 2019.

9. Ministry of Health, Labour and Welfare. Trends in leading causes of death Retrieved from http://www.mhlw.go.jp/english/database/db-hw/populate/ dl/03.pdf . Accessed 11 June 2019.

10. Mayumi H. Progress in Cancer control and participation of citizens and patients in Japan (in Japanese). Social security news department, the Yomiuri Shimbun. J Natl Inst Public Health. 2008;57(4):362-5.
11. Ministry of Health, Labour and Welfare. History of Cancer Control in Japan (in Japanese). Retrieved from https://ganjoho.jp/data/reg_stat/ statistics/brochure/2011/cancer_control_en.pdf . Accessed 11 June 2019.

12. National Cancer Center. CANCER STATISTICS IN JAPAN-2015. Retrieved from https:/ganjoho.jp/en/professional/statistics/brochure/2015_en.html. Accessed 11 June 2019.

13. Patkar V, Hurt C, Steele R, Love S, Purushotham A, Williams M, et al. Evidence-based guidelines and decision support services: a discussion and evaluation in triple assessment of suspected breast cancer. Br J Cancer. 2006;95(11):1490-6. https://doi.org/10.1038/sj.bjc.6603470.

14. Nakayama T. Clinical Practice Guidelines: Present and Future (in Japanese). J Tokyo Wom Med Univ. 2018;88(E1):E2-E9. doi: https://doi.org/10.24488/ jtwmu.88.Extra1_E2.

15. Mast KR, Salama M, Silverman GK, Arnold M. End-of-life content in treatment guidelines for life-limiting diseases. J Palliat Med. 2004:7(6): 754-73. https://doi.org/10.1089/jpm.2004.7.754.

16. Krippendorff K. Content analysis: an introduction to its methodology. 3rd ed. Thousand Oaks, CA: Sage Publications Inc; 2013.

17. Drisko J, Maschi T. Content analysis: pocket guide to social work research. New York: Oxford University Press; 2015.

18. Toho University Medical Net Center. Clinical practice guidelines information database (in Japanese). Retrieved from http://guideline.jamas.or.jp/. Accessed 11 June 2019.

19. Japan Council for Quality Health Care. Medical Information Network Distribution Service (in Japanese). Retrieved from https://minds.jcahc.or.jp/ medical guideline/quideline_list. Accessed 11 June 2019.

20. Sato Y, Nakayama T, Satoh T, et al. Preferred information media for providing clinical practice guideline to physicians in Japan: a needs assessment study by the medical information network distribution service (MINDS) in Japanese. Gen Med. 2006;7(2):45-51.

21. Japanese Society for Palliative Medicine. Evidence-based cancer pain treatment guidelines conforming to medicine (in Japanese). 1st ed. Tokyo: Shinko trading publication Department of Medical Books co. In: Ltd; 2000.

22. Japanese Society for Palliative Medicine. Guidelines for drug therapy of cancer pain (in Japanese). Retrieved from http://www.jspm.ne.jp/guidelines/ pain/2010/. Accessed 11 Jun 2019. Accessed 11 June 2019.

23. Yamamoto R, Kizawa $Y$, Nakazawa $Y$, et al. Outcome evaluation of the palliative care emphasis program on symptom management and assessment for continuous medical education: nationwide physician education project for primary palliative care in Japan. J Palliat Med. 2015; 18(1):45-9. https://doi.org/10.1089/jpm.2014.0122.

24. National Cancer Center. Cancer Information (in Japanese). Retrieved from http://ganjoho.jp/public/index.html. Accessed 11 June 2019.

25. Japanese Society for Palliative Medicine. Clinical Guidelines for Palliative Sedation Therapy (in Japanese). Retrieved from https://www.jspm.ne.jp/ guidelines/sedation/sedation01.pdf. Accessed 11 June 2019.

26. Japanese Society for Palliative Medicine. Clinical Guidelines for Gastrointestinal Symptoms in Cancer Patients (in Japanese). Retrieved from https://www.spm. ne.jp/guidelines/gastro/2011/index.php. Accessed 11 June 2019.

27. Japanese Society for Palliative Medicine. Clinical Guidelines for Respiratory Symptoms in Cancer Patients (in Japanese). Retrieved from https://www. jspm.ne.jp/guidelines/respira/2011/index.php. Accessed 11 June 2019.

28. Japanese Society for Palliative Medicine. Clinical Guidelines for Infusion Therapy in Advanced Cancer Patients (in Japanese). Retrieved from https:/wwww.jspm.ne.jp/ guidelines/glhyd/2013/index.php?isbn=9784307101592. Accessed 11 June 2019.

29. The Japanese Urological Association. Practice guideline for prostate cancer in 2012(in Japanese). Tokyo: Kanehara \& Co., Ltd,.

30. Caraceni A, Hanks G, Kaasa S, et al. Use of opioid analgesics in the treatment of cancer pain: evidence-based recommendations from the EAPC. Lancet Oncol. 2012;13:e58-68. https://doi.org/10.1016/S1470-2045(12)70040-2.

31. Fowell A, Johnstone R, Finlay IG, Russell D, Russell IT. Design of trials with dying patients: a feasibility study of cluster randomization versus randomized consent. Palliat Med. 2006;20(8):799-804. https://doi.org/10. 1177/0269216306072554

32. Piggott M, McGee H, Feuer D. Has CONSORT improved the reporting of randomized controlled trials in the palliative care literature? Palliat Med. 2004;18(1):32-8. https://doi.org/10.1191/0269216304pm857oa.

33. Washington $K T$, Parker Oliver D, Gage LA, Albright DL, Demiris G. A multimethod analysis of shared decision-making in hospice interdisciplinary team meetings including family caregivers. Palliat Med. 2016;30(3):270-8. https://doi.org/10.1177/0269216315601545. 